\title{
Planejamento de currículo na Educação Física: possibilidades de um projeto coletivo para as escolas públicas de Uberlândia/Minas Gerais
}

\begin{abstract}
Resumo: Este trabalho é parte de minha investigação de mestrado, desenvolvida no contexto de um processo de formação continuada denominado Planejamento Coletivo do Trabalho Pedagógico (PCTP). O objetivo aqui é apresentar: algumas das reflexões sistematizadas no PCTP à luz de uma concepção crítica de currículo; e uma breve descrição do momento histórico em que se deu a reunião deste grupo, com afinalidade de construir um projeto político para a Educação Física Escolar, enfocando, especialmente, o contexto político da Rede Municipal de Ensino.

Palavras-chave: Educação Física, currículo, planejamento.
\end{abstract}

Neste trabalho apresentamos parte de uma investigação desenvolvida durante o curso de mestrado/ que teve origem a partir de uma trajetória de trabalho docente compartilhada por um grupo de professores e professoras de Educação Física de Uberlândia/MG, na perspectiva de consolidar um projeto coletivo para o ensino deste componente curricular nas redes públicas locais.

Realizado entre os anos 2000 e 2003, este estudo pretendeu, dentre outros objetivos, dar continuidade ao registro histó rico do trabalho coletivo desenvolvido a partir da sistemática de

\footnotetext{
* Rede Municipal de Ensino de Uberlândia Minas Gerais.

1 AMARAL, G. A. "Planejamento de Currículo na Educação Física: possibilidades de um projeto coletivo para as escolas públicas de Uberlândia/Minas Gerais". Dissertação de mestrado, PUC/SP: 2003
}

Movimento, Porto Alegre, v. 10, n. 1, p. 133-155, janeiro/abril de 2004 
intervenção político-pedagógica que, associada a um processo contrahegemônico de formação continuada de educadores, foi denominada Planejamento Coletivo do Trabalho Pedagógico (PCTP). ${ }^{2}$

O PCTP é fruto de um trabalho de assessoria desenvolvida pelo Núcleo de Estudos em Planejamento e Metodologias de Ensino da Cultura Corporal (NEPECC/UFU), inicialmente à equipe de professores de Educação Física da Escola de Educação Básica da Universidade Federal de Uberlândia (ESEBA/UFU), em 1993, e, posteriormente, a partir de 1996, estendido à Rede Municipal de Ensino de Uberlândia (RME/UDI).

Neste artigo apresentamos algumas contribuições ao processo de produção de Currículo na Educação Física Escolar, de acordo com o referencial teórico e metodológico do PCTP, produzidas ao longo dos anos de existência desta experiência de trabalho coletivo e que foram agora organizadas no decurso da referida investigação, com a finalidade de apontar as possibilidades de materialização do planejamento de currículo, fundamentado numa perspectiva crítica de educação, contando a participação efetiva dos professores envolvidos no PCTP.

Para tanto, após uma apresentação breve do percurso metodológico do estudo, segue uma descrição breve da história desta sistemática junto aos professores de Educação Física da RME/UDI e do contexto político em que se desenvolveu a trajetória deste grupo. Compreender o movimento, a dinâmica e os conflitos que permearam esta história é fundamental para que não seja feita uma leitura linear e mecânica da mesma, minimizando o risco de pensar a realidade fora das contradições, da diversidade que lhe são constitutivas.

2 A descrição e análise crítica deste processo de trabalho coletivo, iniciado em 1993, foi registrada em pesquisa elaborada na Pontifícia Universidade Católica de São Paulo, registrada em defendida em marco de 2001 pero titulo: Intervenção Politico-Pedagógica: A necessidade do planejamento de currículo e da formação continuada para a transformação da prática educativa, como requisito para obtenção do título de Doutor pelo Programa de Pós-graduação em Educação: Currículo.

Movimento, Porto Alegre, v. 10, n. 1, p. 133-155, janeiro/abril de 2004 
Em seguida, apresentamos o resultado da sistematização, provisória e inacabada, do processo de produção de currículo desenvolvido no contexto do PCTP, tendo como fundamentos, dentre outros, uma concepção de formação humana ampliada e uma reflexão crítica sobre a prática pedagógica.

\section{Percurso metodológico}

A pesquisa em educação, assim como qualquer outra prática social, apresentou em sua trajetória um compromisso epistemológico com o modelo científico da racionalidade instrumental moderna, caracterizada, entre outros aspectos, pela unicidade, universalidade e neutralidade da verdade científica, ou seja, pela definição de um único método investigativo do real. Entretanto, a competência destas referências para expressar a existência social, cultural e humana e a própria realidade educacional, vem sendo contestada pela filosofia, pela sociologia e pela antropologia, dentre outras áreas, que apontam outro tipo de racionalidade na construção do conhecimento (Leite, 2001).

A complexidade da condição humana implicou na ampliação dos limites de cientificidade definidos na modernidade, aceitando o fato de que...

As investigações sobre o homem e seu agir, mostraram que não existe uma verdade universal e neutra sobre o homem, que o sujeito que conhece e aquele que é conhecido são marcados profundamente por suas identidades culturais, entendidas, aqui, como inserção em uma sociedade e em uma história, portadoras de várias identidades: classe social, gênero, raça, etnia, religião e que a ação humana não está sujeita à repetição, previsão, mensuração e experimentação (p. 152).

A crítica generalizada à prática pedagógica e à formação de professores nos moldes da racionalidade técnica (uma vez que a sala de aula e a realidade social apresentava-se muito mais complexa do que os pressupostos com que a academia havia, até meados dos anos setenta e oitenta, orientado os professores) deu origem a alternativas diferenciadas para se tratar o assunto, colocando em destaque a necessidade do estabelecimento de processos de colaboração entre pesquisadores e professores.

Aspectos comumente chamados "conscientização", "criatividade", "inovação", etc. estão presentes, em grande medida, nos fenômenos educacionais, cujas especificidades qualitativas costumam ser negligenciadas pelos investigadores tradicionais, especialmente

Movimento, Porto Alegre, v. 10, n. 1, p. 133-155, janeiro/abril de 2004 
quando situações de ação e decisão manifestam-se no plano da significação e da elucidação que os instrumentos clássicos não apreendem (Brandão, 1987; Jimenez Pena, 1999).

Assim, a partir de um movimento de busca de uma aproximação entre professor e pesquisador, entre pesquisa acadêmica e cotidiano, pesquisa e ação pedagógica (Zeichner, 2000; Ludke, 2001), surgem novas possibilidades metodológicas orientadas para a busca de uma compreensão crítica da dinâmica social, situadas dentro do universo da Pesquisa Qualitativa, que se caracteriza por tomar como ponto de partida a descrição da realidade, com intenção de captar, para além do que é aparência, a essência dos fenômenos. Busca, por sua preocupação como o processo, identificar as relações de forças responsáveis por seu movimento dinâmico e situado.

Uma abordagem qualitativa pressupõe que o pesquisador, ao contrário da visão positivista, esteja despido de planos rígidos para analisar o contexto da investigação (Bogdan \& Biklen, 1994), uma vez que os planos serão delineados à medida que a realidade vai sendo descrita e compreendida à luz do referencial teórico. A estruturação dos passos da pesquisa se dá no processo de utilização dos instrumentos de coleta de dados, acompanhando sistematicamente o movimento em torno dos fenômenos sociais ocorridos com as pessoas envolvidas (Jimenez Pena, 1999).

A realização do presente estudo procurou fundamentar-se neste campo metodológico, partindo do pressuposto básico que um problema de pesquisa dever ser, em primeira instância, um problema da vida prática. Isto quer dizer que a escolha do tema e do contexto de estudo surgiu de interesses e circunstâncias histórica e socialmente condicionados, frutos de determinada inserção no real, nele encontrando suas razões e seus objetivos (Minayo, 1996).

Assim, o trabalho desenvolvido não buscou descrever uma realidade tal como se monta um quebra-cabeça, cuja forma já sabemos de antemão, mas consistiu num exercício de registrar, analisar e interpretar um determinado momento da história de um projeto coletivo em construção desde 1993.

A leitura do momento histórico descrito foi fundamentada numa abordagem interpretativa, vinculada à utilização da observação participante, que usa como instrumento privilegiado

Movimento, Porto Alegre, v. 10, n. 1, p. 133-155, janeiro/abril de 2004 
de aproximação à realidade a narração contínua dos fenômenos observados, mas vai além, procurando questionar os significados dos mesmos no contexto onde são produzidos (Jimenez Pena, 1999). Na pesquisa educacional este tipo de abordagem se justifica pela crença de que o meio social-politico e seus significados têm estreita relação com a forma como as pessoas envolvidas pensam e agem.

O interesse na investigação se deu muito mais pela particularidade do fenômeno observado do que pela generalização das conclusões, porque a abordagem qualitativa não se presta a informações conclusivas, mas surge como reflexo fiel do estilo singular de indagar e comunicar do próprio investigador. (Gomes, 1994).

\section{Apresentando o Planejamento Coletivo do Trabalho Pedagógico no contexto da Rede Municipal de Ensino de Uberlândia/MG}

A história desta experiência teve início com a aproximação entre a equipe de Educação Física da ESEBA/UFU e os professores Gabriel Munoz Palafox e Dinah Terra do Núcleo de Estudos em Planejamento e Metodologias de Ensino da cultura Corporal (NEPECC), da Universidade Federal de Uberlândia (UFU), em 1993. A partir de um interesse comum em começar a discutir coletivamente a prática pedagógica à luz de referenciais filosó-fico-pedagógicos, com a perspectiva de transformá-la, este grupo de professores deu início a um processo de organização coletiva orientada para o estudo e o planejamento. Foi, então, instituída uma assessoria pedagógica permanente, com a finalidade de refletir sobre a prática, para pensar sistematicamente suas possibilidades de transformação.

Na Rede Municipal de Ensino (RME), o ponto de partida que possibilitou a organização da área de Educação Física foi a reunião de um grupo de professores em torno da elaboração de uma Proposta Curricular, no ano de 1996. Neste processo, o grupo de Educação Física sentiu a necessidade de contar com uma assessoria acadêmica para orientar a sistematização teórica da Proposta. Foi nesse contexto que se deu o encontro com o professor Gabriel Humberto Munoz Palafox, docente da Universi- 
dade Federal de Uberlândia - UFU, que já era conhecido por vários professores e vinha também acompanhando o trabalho da Educação Física na ESEBA/UFU.

No final de 1996, pelo esforço deste grupo pioneiro, foi apresentada oficialmente uma versão preliminar da Proposta Curricular de Educação Física da RME. Posteriormente, este documento passou a ser denominado Plano Básico de Ensino (PBE/EF) ${ }^{3}$ tornando-se, na verdade, a referência identitária da área, não somente no contexto da RME/UDI, mas também da ESEBA/UFU, a partir do trabalho interinstitucional coordenado pelo NEPECC/UFU.

Considerando que, naquele momento inicial, a participação dos professores nos encontros era obrigatória, uma vez que seria necessário ampliar a participação dos professores na construção da proposta, garantir o espaço coletivo e a formação continuada, a partir de 1997 as escolas foram orientadas a reorganizar seu quadro de horários de tal forma que cada área tivesse um dia livre por semana, o qual ficaria destinado às reuniões mensais no Centro de Estudos e Projetos Educacionais - CEMEPE.

Devido a uma série de dificuldades, e mesmo sendo obrigatória a participação naquele momento, o trabalho que chegou a atingir mais de $80 \%$ do professores naquele momento, enfrentou ainda inúmeros desafios de natureza política e administrativa, mas também de resistências internas. Segundo avaliação do próprio grupo, isto se deu por motivos diversos, tais como: os professores que trabalhavam também em outras redes de ensino (estadual ou particular) não tinham condições para participar das reuniões; algumas escolas apresentavam dificuldades para organizar seu quadro de horários de forma a liberar o professor no dia determinado para a área; mesmo com o caráter de obrigatoriedade era possível descumprir a determinação da secretaria, sem prejuízo para aqueles que não desejavam se incorporar ao trabalho.

\footnotetext{
3 A respeito do conteúdo e finalidades deste documento ver, nesta revista, artigo de MUNOZZ PALAFOX.
}

Movimento, Porto Alegre, v. 10, n. 1, p. 133-155, janeiro/abril de 2004 
Além destes aspectos, logo no início de 1998, o espaço de formação e planejamento coletivo na Rede Municipal foi, temporariamente, interrompido devido a uma decisão da Secretaria de Educação. A mudança da gestão municipal naquele momento provocou alterações significativas e definiu novos direcionamentos da política educacional. ${ }^{4}$

Desta forma, todas as reuniões de área foram canceladas entre os meses de abril e julho, somente sendo retomadas no segundo semestre, sob direção de uma nova equipe do CEMEPE, indicada pela SME/UDI. Porém, a presença de um coordenador de cada área foi mantida, o que permitiu a alguns grupos manterem-se organizados.

Sem dúvida alguma, esta ruptura afetou sensivelmente a continuidade do trabalho, a disposição e o ânimo dos professores, que viam suas expectativas frustradas por interesses contrários àqueles que os motivara inicialmente. A partir daí foram surgindo diversos problemas que dificultaram a reorganização dos professores, embora o grupo de Educação Física tenha conseguido organizar-se, mobilizando-se para retomar as atividades junto ao assessor, exigindo que fosse mantida a mesma orientação que o trabalho vinha tendo.

Mesmo diante de dificuldades como essas, ao final de 1998, com a sistematização de uma Estratégia de Ensino $^{5}$ com a temática Jogo, foi organizado o primeiro Plano Anual de Educação Física (PAEF) contando a participação direta de 27 pessoas, as quais trabalharam intensivamente para elaborar o documento.

Posteriormente, a elaboração de planos anuais tornou-se uma das diretrizes do PCTP, consolidando-se como um dos Instrumentos de Mediação Comunicativa $(\mathrm{IMC})^{6}$ desenvolvidos para atender à necessidade de organização e registro do planejamento. $\mathrm{O}$ PAEF tem como objetivos: 1) identificar os problemas e difi-

4 Naquele momento, como parte de um projeto pessoal da então Secretária de ensino, foi feito um investimento no Ensino Religioso, de acordo com uma concepção de "Orientação para a Vida", atrelada ao ensino de valores humanos.

5 Estratégia de Ensino: sistematização do Planejamento (onde, com que, quando e como) de um processo de ensino (ciclo de aulas) desenhado para atingir uma ou várias competências educacionais. Numa Estratégia pode ser prevista a utilização de um ou mais Estilo/técnica de ensino. Para maiores detalhes sobre as Estratégias ver nesta revista artigo de MUÑOZ PALAFOX.

6 Os vários instrumentos construídos são utilizados para o registro e socialização das experiências de ensino, para organização dos conteúdos curriculares e para apresentação de uma leitura das dificuldades cotidianas enfrentadas.

Movimento, Porto Alegre, v. 10, n. 1, p. 133-155, janeiro/abril de 2004 
culdades considerados mais importantes pelo grupo, apresentando idéias e propostas para sua superação, de acordo com a leitura da realidade escolar; 2) apresentar as Estratégias de Ensino já sistematizadas e a teoria de aprendizagem subjacente.

Como conseqüência das rupturas e descontinuidades políticas, que afetavam diretamente os rumos da educação no município, entre os anos de 1998 e 2000 o trabalho de formação com os professores, tanto na Educação Física quanto nas demais áreas, foi sendo gradativamente esvaziado.

Mantendo a prática de realizar sucessivos diagnósticos da realidade educacional e do trabalho de formação continuada em andamento, começou a ser discutido no grupo de Educação Física o impacto do planejamento e implementação das Estratégias de Ensino, bem como a necessidade de ampliar e organizar novos espaços de socialização e de análise coletiva do trabalho realizado pelos professores, tanto da RME/UDI, quanto da ESEBA/UFU.

Sintonizados com a sistemática construída como resultado da prática da formação continuada (PCTP), surgiu a idéia de incorporar à sua estrutura um espaço científico-pedagógico de debate e de divulgação do trabalho realizado no cotidiano escolar pelos professores. Em 2001, sob coordenação do NEPECC, foi elaborado o projeto pedagógico e financeiro de caráter inter-institucional que instituiu a realização do Simpósio de Estratégias de Ensino em Educação/Educação Física.

Naquele ano, com a mudança de gestão na administração municipal e na Secretaria de Educacão, apareceram novas expectativas de trabalho quanto à possibilidade de retomada dos espaços coletivos de formação, agora na perspectiva da reconstrução da escola pública em Uberlândia, na direção de sua efetiva democratização. ${ }^{8}$

7 Já foram realizadas três edições do Simpósio (2001, 2002 e 2003).

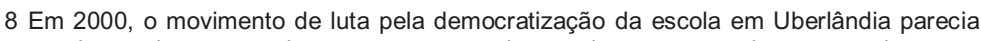
er alcançado seu grande momento com a derrota dos setores mais conservadores e a vitória de um projeto político que teve o apoio dos partidos de esquerda do município.

Movimento, Porto Alegre, v. 10, n. 1, p. 133-155, janeiro/abril de 2004 
Nesse contexto, participando ativamente das discussões acerca da necessidade de implementar um novo projeto para a educação em Uberlândia e aproveitando o momento político aparentemente favorável, o grupo de professores participantes das reuniões de área no CEMEPE (em média 30 pessoas) já apontava, desde o início da nova gestão, a necessidade de medidas emergenciais voltadas, imediatamente, para a elevação da motivação profissional, articuladas com a construção de um projeto político-pedagógico que incluísse a luta por uma política de ajuste salarial. ${ }^{9}$

Por outro lado, o grande desafio do PCTP continuava sendo abrir canais de comunicação para que o projeto político-pedagógico para a Educação Física fosse ampliado junto aos professores, aspecto que implicava uma revisão/atualização do Plano Básico de Ensino, considerando que novas contribuições eram acrescentadas ao planejamento coletivo e ao currículo a partir da elaboração e implementação de novas Estratégias de Ensino pelos professores.

A partir desta constatação, durante a organização do II Simpósio de Estratégias de Ensino, em 2002, a equipe interinstitucional reunida no NEPECC/UFU, apontou como prioridade para o ano seguinte a atualização do Plano Básico de Ensino.

Diante do quadro aqui apresentado, duas questões principais serviram de referência.

A nova conjuntura política, aparentemente favorável, traria, efetivamente, melhores condições para a continuidade e ampliação do trabalho coletivo, de acordo com a lógica proposta no PCTP?

É possível apontar, a partir da experiência do PCTP em Uberlândia, os elementos teóricos e metodológicos que sinalizam as possibilidades de materialização de um processo de produção de currículo para a Educação Física Escolar?

9 Vale destacar quem embora o grupo de EF tenha lutado para ampliar esta discussão e ver efetivada uma nova política, não obteve êxito nesse sentido. Somando a isto outros fatores, os servidores municipais iniciaram, no mês de junho, uma greve geral que durou 30 dias, esvaziando mais uma vez os encontros entre os professores no CEMEPE.

Movimento, Porto Alegre, v. 10, n. 1, p. 133-155, janeiro/abril de 2004 
Como não nos é possível, dentro dos limites deste artigo, apresentar todas as discussões construídas em torno destas duas questões, nos deteremos aqui na apresentação de alguns apontamentos que nos permitiram avançar na busca de respostas à segunda questão.

\section{Introdução à concepção de Currículo: contribuições ao referencial teórico-metodológico em construção}

Tradicionalmente os estudos e investigações acerca do Currículo procuraram responder a questões como: que tipo de experiência é significativa para os alunos vivenciarem? Quais objetivos são relevantes para o ensino? Que conhecimento e que "espaços culturais" devem ser colocados ao alcance dos estudantes? Como tudo isto pode ser lavado às escolas de forma prática e coerente?

Esta tradição esteve ligada a uma determinada forma de entender a trajetória educativa a partir dos aspectos de ordenação e sequenciação, centrando-se mais no ensino do que na aprendizagem. Isto trouxe para o centro da discussão conceitos como programa, instrução, método em detrimento de categorias como cultura, ideologia, conflito, dentre outros, e terminaram conformando também uma determinada forma de conceber a própria instituição escolar. Por este motivo, pode-se afirmar que não há uma concepção de currículo desvinculada de uma visão política sobre a escola.

No campo acadêmico vamos encontrar questões que giram em torno da elaboração de modelos e procedimentos, do estudo das formas de racionalidade que podem ser encontradas por trás da relação entre decisões e ações e, mais nas últimas décadas, estudos sobre as possibilidades de construção de uma fundamentação para justificar um outro tipo de experiência educativa. Em todas estas formulações, política, administração e pedagogia compõem o território no qual se move o campo do currículo.

Diversas classificações de concepções de currículo têm sido apresentadas, de acordo com diferentes focos de investigacão. Como exemplo podemos citar aquela baseada na identificação das correntes filosóficas e sociológicas, onde o currículo pode ser apreendido como 1) Formal - corresponde ao conjunto de diretrizes, planos e propostas pedagógicas prescritos no currículo oficial. Sustenta-se numa concepção sistêmica/positivista de

Movimento, Porto Alegre, v. 10, n. 1, p. 133-155, janeiro/abril de 2004 
Educação e Sociedade. 2) Oculto - representa o "não dito", os aspectos ideológicos do processo. Pode ser compreendido naquilo que a comunidade traz, carregado de sentidos e que interfere nos processos de controle/resistência social, comunicação/linguagem e convivência/interação, nem sempre explicitados socialmente. 3) Em Ação - aquilo que acontece na realidade vivida (no cotidiano escolar e na sala de aula). Nestes dois últimos podem ser encontradas contribuições advindas de correntes praxiológicas, marxista, pósestruturalista e pós-marxista.

Independentemente do significado e sentido atribuído ao Currículo, pode-se afirmar que, em última instância, ele é determinado por interesses, concepç̃es e enfoques de conhecimento científico e filosófico que, longe de serem "elucubrações teóricas abstraías", ou teoria "pura", o que poderia ser considerado inútil à prática, são fontes de conhecimentos que estão na raiz das matrizes curriculares, orientando, tanto o pensamento pedagógico, quanto às políticas de currículo.

Assumir uma perspectiva de trabalho pedagógica fundamentada numa abordagem dinâmico-dialógica de Educação e Educação Física/Esporte significa atuar na perspectiva deformação de sujeitos críticos, com fundamentos teórico-práticos suficientes para discernir: 1) quais os fatores objetivos e subjetivos que determinam a realidade social desde os pontos de vista filosófico e cientifico; 2) a favor de quem e contra quem se está, no momento de optar e exercer nossas ações profissionais, explicitando num projeto politico-pedagógico as perguntas: por que, como, onde e com quem se constrói a proposta de educação que defendemos para todos os seres humanos. (Munoz Palafox, 1996)

Nesse sentido, é preciso reafirmar a importância do papel da escola no processo de construção do conhecimento, processo esse desenvolvido em conjunto por alunos e professores em suas tentativas de responder aos desafios de suas realidade e de lutar por uma sociedade menos dividida. A concepção de formação humana aceita aqui, enfatiza a exigência de uma transformação substancial nas relações e nas hierarquias da escola, substituindo o verticalismo que caracteriza as decisões pela discussão coletiva e pela ampla participação de todos os grupos e setores interessados(Moreira, 1994).

Tornar a escola democrática não desvia, obrigatória e naturalmente, o foco da formação para a produção de conhecimento, mas abre caminho para esforços conjuntos no sentido de ultrapassar, definitivamente, aquela visão de que o conhecimento científico é um conteúdo teórico de caráter técnico, que deve ser aplicado no campo profissional para solução instrumental de 
problemas. Concepção presente no modelo de profissionalismo que se estabeleceu ideologicamente no contexto da modernidade, a partir das ciências físico-naturais, enraizando-se também na área da Educação (Contreras, 2002).

É esse tipo de racionalidade instrumental que se faz presente no modelo curricular denominado empírico-analítico, cujo interesse constitutivo é a ação sobre o objeto, na sentido de sua dominação que pode ser necessário em se tratando da busca de domínio do homem sobre a natureza (prática produtiva), porém, problemático quando estabelecido como única referência no campo da formação humana, como no caso da Educação.

Porém, o conceito de formação humana ampliada não se esgota no questionamento ao domínio da racionalidade técnica nos processos de educação. É necessário que o processo educativo esteja orientado para alcançar a existência humana em sua totalidade, ou seja, para além de sua dimensão instrumental, incorporar outras dimensões que vêm sendo apontadas como constitutivas desta existência e como referências para se alcançar a emancipação das classes oprimidas.

Sabemos que o conhecimento científico e filosófico somente adquire efetivo sentido/significado para o professor quando este é capaz de utilizá-lo, porém, refletindo sobre ele e transfor-mando-o, como resultado de sua própria prática social (pessoal e profissional). Em outras palavras, a existência do educador se efetiva como "práxis" crítica e emancipatória quando mediada pelo conhecimento científico e filosófico constantemente adquirido e recriado pelo próprio educador.

Dentro desta linha de reflexão, Severino (2002), numa interessante e recente análise dialética de cunho filosófico-antropológico, considera que a existência humana se manifesta na forma de uma prática tridimensional onde o conhecimento pode adquirir diferentes sentidos e significados. Esta prática tridimensional é delineada por 3 esferas dialeticamente interrelacionadas:

A prática produtiva (o sujeito se dirige à natureza física, seu primeiro ambiente natural, e estabelece uma relação de troca e apropriações fundamental para sua sobrevivência), política (a esfera social com a qual precisa continuamente interagir para sobreviver como membro do grupo) e simbolizadora (relações estabelecidas com o ambiente formado pelas referências da sua subjetividade: a cultura simbólica) (Severino, 2002, p. 47).

Movimento, Porto Alegre, v. 10, n. 1, p. 133-155, janeiro/abril de 2004 
Cada uma dessas esferas representará as fontes de interesse e de conhecimento que motivarão a ação humana, dependendo do nível e contexto de desenvolvimento dessas esferas e das condições históricoculturais em que tal ação encontra-se inserida:

A prática simbólica ou simbolizadora interfere nas esferas produtiva e política da interação humana na medida em que se torna fonte de saber e de conhecimento utilizado para regular a vida sócioeconômica e ético-política, seja na busca da liberdade e a autonomia humana, ou, contrariamente, como fonte de dominação (controle social) e de manipulação individual e/ou social, em nome de interesses econômicos e políticos associados, dentre outros, às contradições de classe social, de gênero, de etnia/raça etc.

Destaca-se, assim, a criação/existência da ideologia como fonte simbolizadora capaz de apresentar à consciência uma realidade deturpada, mas que atende aos interesses/beneficio de alguém, e de produzir, também, "falsas consciências" pela ação da publicidade ou da manipulação da opinião pública (propaganda) (Severino, 2000: 54).

Aceitando o pressuposto da prática tridimensional da existência humana, perguntamos, então, quais seriam as competências humanas necessárias para promover o exercício de uma "práxis" como relação teórica e prática indissociável, capaz de contribuir com a transformação e o crescimento da humanidade? (Munoz Palafox et ai. 2004).

De acordo com Habermas (apud Kunz,1994), pode-se afirmar que a transformação individual e social encontra-se associada à aquisição de três competências humanas, fundamentais para produzir e acumular conhecimento e, também, para contribuir praticamente com a ação transformadora da humanidade, motivo pelo qual tornam-se, invariavelmente, alvo de uma formação humana numa perspectiva ampliada.

Denominadas de Instrumental, Social e Comunicativa, cada uma destas competências incorporam conhecimentos científicos e filosóficos que procuram explicar e transformar as esferas produtiva, social e simbolizadora da existência humana anteriormente citadas.

Movimento, Porto Alegre, v. 10, n. 1, p. 133-155, janeiro/abril de 2004 
A Competência Instrumental é adquirida ao longo da vida mediante a internalização teórico-prática de conhecimento e pela acumulação de experiência orientadas para agir no mundo do trabalho e do "não-trabalho" por meio da aquisição de destrezas e técnicas racionais e eficientes (Kunz, 1994, p. 38).

Na Educação Física, a competência instrumental relaciona-se com o conhecimento advindo das ciências exatas e da natureza no contexto de transformação da prática produtiva, encontra-se associada à aquisição de conhecimento e experiência técnico-instrumentalnormativa relevante para que o indivíduo, em sua práxis social, utilize-se de habilidades físicas, técnicas, táticas, administrativas e organizacionais, voltadas, por um lado, para atender necessidades operacionais dessa mesma prática produtiva, como é o caso do domínio de técnicas e táticas do esporte, da dança e de outras manifestações corporais.

Como alvo da formação humana no contexto da Educação Física Escolar, a Competência Instrumental é internalizada e desenvolvida para alcançar uma qualificação necessária para: a) compreender e aplicar criticamente os elementos instrumentais-téc-nico-científicos de uma boa qualidade de vida em termos de aptidão biológica (psicofísica); b) aproveitar, de forma eficaz e eficiente, o tempo disponível para o lazer, bem como as práticas simbolizadora e política nos seus aspectos normativos e técnico-ci-entíficos; e) construir as bases motoras, técnicas, táticas e psico-emocionais para a realização de algum tipo de atividade (esportiva ou não) que, por ventura, venha a adquirir um caráter profissional no seu mundo de trabalho.

O desenvolvimento da Competência Social tem como objetivo contribuir para um agir solidário e cooperativo (Kunz, 994, p. 39). É internalizada a partir de processos de reflexão crítica sobre a realidade, associada à apropriação de conhecimentos que promovam uma adequada análise e interpretação das relações socioculturais, dos problemas, das contradições e dos antagonismos sociais.

Para nós, o estudo e colocação em prática dos conteúdos relacionados com a corporeidade humana nos contextos sóciohistórico-culturais do jogo, do esporte, da ginástica, da expressão corporal, que inclui a dança, e das lutas corporais, dentre outras manifestações semelhantes (objeto da Educação Física Escolar), devem promover o desenvolvimento e aprimoramento da Competência Social, no processo de implementação de Estratégias de Ensino capazes de incentivar a análise filosófi-

Movimento, Porto Alegre, v. 10, n. 1, p. 133-155, janeiro/abril de 2004 
ca, histórica, sociológica e antropológica das práticas produtiva, social e simbolizadora da existência relacionadas com as diferentes manifestações da corporeidade (Munoz Palafox et al. 2004).

A Competência Comunicativa, (Kunz,1994) relaciona-se com a extrema necessidade de que o aluno aprenda e saiba comunicar-se e entender a comunicação do outro. A aprendizagem desta competência, na qualidade de processo reflexivo, "desencadeia iniciativas de pensamento crítico" (p. 39).

A Competência Comunicativa é colocada em prática durante o exercício da fala, da produção de conhecimento científico, filosófico ou artístico, no planejamento e implementação coletiva de estratégias de ensino que incentivam o debate e a crítica, com objetivo de qualificar o indivíduo para a prática de uma ação comunicativa permeada pela aquisição de uma boa capacidade de discernimento e de julgamento crítico.

Orientados por esta concepção de formação humana, adotada no contexto da formação continuada de professores no PCTP, pode-se afirmar que o sentido e significado atribuído ao Currículo, numa perspectiva dinâmico-dialógica pode ser assim definido:

"Uma Estratégia de ação intersubjetiva dotada de procedimentos metodológicos (inclusive de controle do processo), que se efetiva no interior de um determinado sistema educativo com a finalidade de":

a) Definir princípios ético-político-pedagógicos,

b) Selecionar e filtrar informações/conhecimentos advindos do contexto sociocultural de acordo com a política cultural adotada para construção de saberes escolares sistematicamente organizados;

c) Compartilhar as informações/conhecimentos coletados, objetivando a sua internalização crítica por educadores/ as e alunos/as, por meio de experiências de Ensino-aprendizagem criadas para essa finalidade, de acordo com os níveis/estágios de compreensão/escolarização adotados;

d) "Manter o sistema em avaliação constante, criando e utilizando mecanismos e metodologias diversas." (Muñoz Palafox, 2001, p. 135136).

Movimento, Porto Alegre, v. 10, n. 1, p. 133-155, janeiro/abril de 2004 
Neste enfoque, a construção de uma proposta de ensino de um determinado componente curricular, bem como a intervenção na realidade concreta, ultrapassa os limites daquela área de conhecimento ou disciplina, além de tomar como pressuposto algumas diretrizes básicas, dentre as quais:

adoção de uma concepção e prática de intervenção político pedagógica inconformada com a ordem vigente;

instituição de um política de formação continuada para construção da autonomia do educador crítico-reflexivo;

superação da divisão entre aqueles que pensam a educação e os que executam - lógica de planejamento crítico ascendente;

produção de saberes escolares e de conhecimento pelos próprios educadores;

desenvolvimento de competências instrumental, social e comunicativa para construção coletiva de conhecimento e para resolução de problemas socialmente relevantes.

Como estratégia de intervenção crítica, o currículo engloba um processo dinâmico e mutável de produção de saberes, cuja mediação entre o idealizado e a realidade concreta se dá no campo do planejamento coletivo, com vistas à instauração, entre os educadores, de uma prática social efetivamente comprometida com a transformação contínua e progressiva dessa realidade.

Sua materialização no cotidiano e nas práticas político-pedagógicas (currículo em ação) não pode ser apreendido a partir simplesmente do que está dito ou prescrito, uma vez que a totalidade na qual uma determinada realidade está inserida é muito mais complexa do que aquilo que se pode dizer ou escrever a respeito. Este aspecto, dentre outros, nos levou a construção da idéia de Curricularidade, incorporando a noção de provisoriedade/inacabamento, bem como a necessidade de sua constante reformulação à luz do estudo de seu impacto na realidade concreta.

Esta Curricularidade apresenta níveis diferentes de generalidade, que podem ser identificados por duas dimensões: uma macro e outra microcurricular. A primeira dimensão, Macrocurricular, inclui os temas curriculares gerais, referen-

Movimento, Porto Alegre, v. 10, n. 1, p. 133-155, janeiro/abril de 2004 
tes à estrutura de todo o currículo no seu conjunto. O estudo dos problemas da realidade educacional, neste campo, se dá a partir dos conhecimentos advindos de áreas como a sociologia, a filosofia e a antropologia.

Constituem elementos macrocurriculares os aspectos: 1) filosófico-políticos (concepções, interação humana, metas, postura profissional); 2) administrativos (organização do trabalho, relações humanas (interações), controle/aproveitamento de recursos materiais e humanos; 3) técnico-científico (organização e seleção de conteúdos, objetivos e metas, metodologias de ensino, recursos didáticos, sistema de avaliação discente, docente, administrativo e do currículo).

A segunda dimensão, Microcurricular, distingue-se da primeira apenas no que diz respeito ao nível de generalidade e refere-se aos problemas relacionados com cada componente curricular em particular. $\mathrm{O}$ fortalecimento das estruturas microcurricular es justifica-se, num primeiro momento, pela necessidade de construção e/ou reconstrução da identidade dos diferentes componentes curriculares dentro do sistema de ensino, para depois proceder a uma análise sobre as possibilidades de construir interfaces entre eles, na busca de uma progressiva redefinição desta abordagem disciplinar para uma outra forma de organização.

\section{Produzindo currículo na Educação Física}

Durante a elaboração da primeira versão do Plano Básico de Ensino foram definidos quatro grandes temas para o ensino deste componente curricular nas escolas (Jogo, Esporte, Ginástica e Dança), por serem, naquele momento, aqueles que estavam mais presentes na realidade concreta. Além deste aspecto, vale ressaltar também que a maioria dos professores participantes dos espaços do planejamento coletivo na época vinham sendo influenciados pela leitura de algumas produções da área que, dentre outros elementos da corporeidade, identificavam, igualmente, estes quatro temas como constituinte do conteúdo da Educação Física escolar. ${ }^{10}$

$10 \mathrm{Um}$ aspecto interessante naquele momento foi a constatação de que, dos quatro temas citados, o Esporte aparecia como aquele a que era dedicado quase $80 \%$ das aulas durante o ano, ficando o jogo com $15 \%$ e a Ginástica e/ou dança com $5 \%$.

Movimento, Porto Alegre, v. 10, n. 1, p. 133-155, janeiro/abril de 2004 
Em 1998, uma professora da Rede Municipal, na tentativa de apropriar-se criticamente do conhecimento advindo das reflexões coletivas, principalmente o estudo das competências educacionais, na perspectiva dialética, ousou experimentar em seu contexto escolar um processo diferenciado de trabalho, utilizando o tema Jogo. Ao apresentar o produto de seu trabalho, foi desenvolvido um processo, até então nunca experimentado, de sistematização da experiência a partir da descrição detalhada dos procedimentos metodológicos adotados, para posterior análise coletiva.

O fruto deste processo foi a definição de uma nova possibilidade de organização e planejamento das aulas e a constatação da necessidade de revisão da distribuição quantitativa dos conteúdos ao longo do ano. A socialização deste trabalho entre os professores promoveu uma mudança significativa no tratamento deste tema junto aos alunos e contribuiu para que o modelo inicial fosse experimentado por vários professores de $\mathrm{I}^{\mathrm{a}}$ à $8^{\mathrm{a}}$ série, com modificações de acordo com o nível dos alunos.

A partir daí começaram a elaboração de Estratégias foram ampliadas para outras temáticas, além de surgirem propostas com temas que não estavam vinculados ao Jogo, ao Esporte, à Ginástica $\mathrm{e}$ à Dança.

Este processo, na medida em que era refletido pelo grupo de professores envolvidos no PCTP, provocou novos desafios: como organizar numa "matriz curricular" os conteúdos da Educação Física, considerando a diversidade de temas/assuntos que vinham sendo abordados nas Estratégias? Seria possível construirmos uma proposta de organização curricular que pudesse apresentar uma visão do desenvolvimento dos conteúdos ao longo de todo o processo de escolarização?

Com estes desafios pela frente, procedeu-se a um esforço coletivo de construção do primeiro Esboço provisório da Microcurricularidade da Educação Física. Os conteúdos não mais ficaram restritos àqueles quatro grande temas e passaram a ser organizados em Eixos Temáticos, os quais buscam responder à ampliação do processo de produção de conhecimento.

O quadro a seguir apresenta a Microcurricularidade organizada para as séries iniciais:

Movimento, Porto Alegre, v. 10, n. 1, p. 133-155, janeiro/abril de 2004 


\begin{tabular}{|c|c|c|c|c|}
\hline \multicolumn{5}{|c|}{ Nepecc/UFU - RME/UDI - Eseba/UFU / ENSINO FUNDAMENTAL } \\
MICROCURRICULARIDADE DA EDUCAÇÁO FísICA ESCOLAR - ESBoço \\
PROVISÓRIO (SITUAÇĀO IDEAL)
\end{tabular}

\section{Considerações finais}

Situados no contexto de uma estratégia de intervenção

crítica, a finalidade do PCTP é agir na realidade concreta, não para restaurar ou manter a ordem social instituída, mas sim, instaurar uma nova cultura político-pedagógica entre os educadores. O sentido de nossa luta coletiva no campo da Educação Física em Uberlândia encontra-se vinculado à necessidade de:

Movimento, Porto Alegre, v. 10, n. 1, p. 133-155, janeiro/abril de 2004 
? procurar valorizar a área como um componente curricular do ensino básico, visando a sua permanência em todos os níveis de ensino da educação básica;

? promover a construção da autonomia pedagógica dos professores, com a criação de espaços de reflexão e de formação permanente onde os saberes escolares possam ser identificados, filtrados e produzidos por eles mesmos;

? contribuir com a transformação necessária da escola, no sentido de que esta passe a servir, efetivamente, aos interesses das classes desfavorecidas, combatendo a cultura individualista e consumista que, dentre outros aspectos, continua valorizando muito pouco, tanto a escola quanto a função do educador.

A busca de uma prática reflexiva e da autonomia docente está vinculada à inclusão dos problemas da prática em uma perspectiva de análise que vai além de nossas intenções e atuações pessoais. Implica um contexto coletivo de ação e participação social e política para tomar decisões frente à realidade. Tais capacidades só podem ser conquistadas através de práticas inovadoras nas quais os professores são livres para experimentar propostas de ensino, sem perder de vista seu compromisso com uma formação crítica e emancipada (Valadares, 2002).

Nesse sentido, entendemos que uma das marcas do PCTP em Uberlândia é que nossa grande luta esteve permeada não somente pela discussão de como deveria ser reconstruída a prática de ensino da Educação Física na escola, mas também pela reivindicação de uma reflexão sobre a possibilidade de mudança da estrutura e funcionamento da escola.

Buscando responder à algumas das inquietações colocadas anteriormente, podemos afirmar que, como resultado da formação continuada e da experiência de planejamento coletivo desenvolvida, é possível construir um processo diferenciado de planejamento de currículo que permita a superação da prática de reprodução de pacotes prontos e/ou "manuais didáticos", aproximando os professores da produção de saberes escolares e da conquista de sua autonomia científica e pedagógica.

Movimento, Porto Alegre, v. 10, n. 1, p. 133-155, janeiro/abril de 2004 
Planificación de curriculo en la educación física: posibilidades de un proyecto colectivo para las escuelas públicas de Uberlándia/Minas Gerais Resumen: Este trabajo hace parte de mi investigación del curso de Master, desarrollada en el contexto de un proceso de formación permanente denominado Planificación Colectiva del Trabajo Pedagógico (PCTP). El objetivo aquí es presentar: algunas de las reflexiones sistematizadas a partir de una concepción crítica de curriculo; y una breve descripción del momento histórico en que se dió la reunión de este colectivo, con la finalidad de construir un proyecto político para el área de la Educación Física Escolar enfocando, especialmente, el contexto político de la Conjería Municipal de Enseñanza.

Palabras-clave: Educación Física, Curriculo,

Planificación.

Planning of curriculum in Physical Education: possibilities of a collective project for the public schools of Uberlándia/Minas Gerais Abstract: This work is a part of my investigation of the course of master, developed in the context of a permanent formation process named collective planning of the pedagogic work (cppw). the target here is to present some of the reflections systematized from a critical conception of curriculum; and a brief description of the historical moment of group meetings, with the purpose of constructing a political project for physical school education area, focusing, specially, the political context of conjería municipal of education. Keywords: Physical Education, Curriculum, Planning.

Movimento, Porto Alegre, v. 10, n. 1, p. 133-155, janeiro/abril de 2004 


\section{Referências}

ARANHA, M. L. de A. Filosofia da Educação - 2ed.vev. e ampl. São Paulo: Moderna, 1996.

BOGDAN, R. \& BIKLEN, S. Investigação Qualitativa em Educação: uma introdução à teoria e aos métodos - Lisboa: Porto Editora, 1994.

BRANDÃO, CR. Repensando a Pesquisa participante. $3^{\text {a }}$ Ed. São Paulo: Brasiliense, 1980.

CAMARGO A. FERREIRA G.; MUNOZ PALAFOX G. Jogo e agir comunicativo: Construindo uma Estratégia de Ensino na Educação Física Escolar no contexto do PCTP da SME/UDI/MG. In: CONGRESSO BRASILEIRO DE CIÊNCIAS DO ESPORTE, 11. 1999, Forianópolis Anais... Goiânia: Colégio Brasileiro de Ciências do Esporte, 1999. p. 158-164. Caderno 2.

CAPARROZ, F.E. Entre a Educação Física na Escola e a Educação Física da Escola: A educação Física como componente curricular. Vitória: UFES, Centro de Educação Física e Desportos, 1997.

CHIZZOTTI, A. Pesquisa em Ciências Humanas e Sociais. São Paulo: Cortez, 1991.

CONTRERAS, J. A Autonomia de Professores. São Paulo: Cortez, 2002.

DELLA FONTE, S. S. O Passado em Agonia: da criação de recucionismos ou sobre como matar a historicidade. In: CAPAR ROZ, F E. (org.) Educação Física Escolar: Política, Investigação e Intervenção. Vol 1 - Vitória, ES: Proteoria, 2001.

FREIRE, R Política e Educação: ensaios - São Paulo: Cortez, 2001.

JIMENEZ PENA, M. DE L. Formação Continuada de Professores na escola: O desafio da mudança a partir da avaliação da aprendizagem. Tese, São Paulo: PUC/SP, 1999.

KUNZ, E. Fundamentos normativos para as mudanças no pensamento pedagógico em Educação Física no Brasil. In: CAPARROZ, F. E. (org.) Educação Física Escolar: Política, Investigação e Intervenção. Vol 1 - Vitória, ES: Proteoria, 2001.

LEITE, S. B. A Ciência como produção cultural/material. In: OLIVEIRA, I. B., LÜDKE, M. A complexa relação entre o professor e a pesquisa. In: ANDRE, M. (ORG.) O papel da pesquisa na formação e na prática dos professores. Campinas: Papirus, 2001.

MINAYO, M. C. O desafio do conhecimento: pesquisa qualitativa em saúde. São Paulo: HUCITEC-ABRASCO, 1996.

MOREIRA A.; SILVA, T. (Org.). Currículo, cultura e sociedade. São Paulo: Cortez, 1994a. MORROW, R. A.; TORRES, C. A. Teoria social e educação: uma crítica das teorias da reprodução. Porto: Apontamentos, 1997.

MUNOZ PALAFOX, G. Educação Física e Ciências do Esporte: Intervenção e Conhecimento na Escola. In: CONGRESSO GOIANO DO COLÉGIO BRASILEIRO DE CIÊNCIAS DO ESPORTE: JORNADA PRÉ-CONBRACE.1999, Goiânia. Anais...Goiânia: FEF/UFG, 1999b. p. 22-28.

Movimento, Porto Alegre, v. 10, n. 1, p. 133-155, janeiro/abril de 2004 
MUNOZ PALAFOX, G. H. Intervenção Político-Pedagógica: A necessidade do planejamento de Currículo e da formação Continuada para transformação da prática educativa. São Paulo: Tese de Doutorado/PUC/SR 2001

MUNOZ PALAFOX, G. O que é Educação Física: uma abordagem curricular. Porto Alegre, Escola Superior de Educação Física. Rev. Movimento, Ano 3, n. 4, 1996/1.

PREFEITURA MUNICIPAL DE UBERLÂNDIA - www.uberlandia.mg.gov.br

PREFEITURA MUNICIPAL DE UBERLÂNDIA/SME - Plano Básico de Ensino - PBE/ EF Mimeo, Uberlândia: 1996

SADI, R. S. A qualidade da Educação Física Escolar. In: CAPARROZ, F. E. (org.) Educação Física Escolar: Política, Investigação e Intervenção. Vol 1 - Vitória, ES: Proteoria, 2001.

SEVERINO, A.J. Filosofia. Coleção Magistério $2^{Q}$ Grau. São Paulo: Cortez, 1992.

VALADARES, J. M. O Professor diante do espelho: reflexões sobre o conceito de professor reflexivo. In: Pimenta e Ghedin (orgs.) Professor Reflexivo no Brasil: gênese e crítica de um conceito - São Paulo: Cortez, 2002.

ZEICHNER, K. Formação de professores: contato direto com a realidade da escola. Presença Pedagógica, v.6, n. 34, jul/ago.2000. 